\title{
LM04 Is Essential for Paraventricular Hypothalamic Neuronal Activity and Calcium Channel Expression to Prevent Hyperphagia
}

\author{
Tariq Zaman, ${ }^{1,2 *}$ Xun Zhou, ${ }^{1 \star}$ Nihar R. Pandey, ${ }^{1}$ Zhaohong Qin, ${ }^{1,2}$ Kianoosh Keyhanian, ${ }^{1,2}$ Kendall Wen, ${ }^{1}$ \\ Ryan D. Courtney, ${ }^{1,2}$ Alexandre F.R. Stewart, ${ }^{2,3}$ and Hsiao-Huei Chen ${ }^{1,2}$ \\ ${ }^{1}$ Center for Stroke Recovery, Ottawa Hospital Research Institute and ${ }^{2}$ University of Ottawa, Ottawa, Ontario K1H 8M5, Canada, and ${ }^{3}$ University of Ottawa \\ Heart Institute, Ottawa, Ontario K1Y 4W7, Canada
}

The dramatic increase in the prevalence of obesity reflects a lack of progress in combating one of the most serious health problems of this century. Recent studies have improved our understanding of the appetitive network by focusing on the paraventricular hypothalamus (PVH), a key region responsible for the homeostatic balance of food intake. Here we show that mice with PVH-specific ablation of LIM domain only 4 (Lmo4) become rapidly obese when fed regular chow due to hyperphagia rather than to reduced energy expenditure. Brain slice recording of LMO4-deficient PVH neurons showed reduced basal cellular excitability together with reduced voltage-activated $\mathrm{Ca}^{2+}$ currents. Real-time PCR quantification revealed that LMO4 regulates the expression of $\mathrm{Ca}^{2+}$ channels (Cacna1h, Cacna1e) that underlie neuronal excitability. By increasing neuronal activity using designer receptors exclusively activated by designer drugs technology, we could suppress food intake of PVH-specific LMO4-deficient mice. Together, these results demonstrate that reduced neural activity in LMO4-deficient PVH neurons accounts for hyperphagia. Thus, maintaining PVH activity is important to prevent hyperphagia-induced obesity.

\section{Introduction}

Hyperphagia (overeating) is a leading cause of diet-induced obesity. The hypothalamus is the key region controlling feeding behavior. Metabolic signals are sensed by interoceptive neurons of the arcuate (ARC) and ventromedial (VMH) nuclei of the hypothalamus that send synaptic projections to the paraventricular hypothalamic $(\mathrm{PVH})$ nucleus where metabolic signals are integrated to control feeding behavior. PVH neurons are excitatory glutamatergic neurons (Ziegler et al., 2002; Rosin et al., 2003;

Received Aug. 9, 2013; revised Nov. 6, 2013; accepted Nov. 11, 2013.

Author contributions: T.Z., X.Z., A.F.R.S., and H.-H.C. designed research; T.Z., X.Z., N.R.P., Z.Q., K.K., K.W., and H.-H.C. performed research; T.Z., X.Z., N.R.P., Z.Q., K.K., K.W., R.D.C., A.F.R.S., and H.-H.C. analyzed data; T.Z., A.F.R.S., and H.-H.C. wrote the paper.

This work was supported by the Canadian Diabetes Association (OG-3-11-3520-HC), Ontario Research Fund, Canada Foundation for Innovation, Heart and Stroke Foundation of Canada (Grants-in-Aid NA6301 and G-130002596), Canadian Institutes of Health Research (MOP-86745 and MOP-130567) and HSFO Centre for Stroke Recovery Catalyst Grants to H.-H.C., H.-H.C. is also supported by the Henry J.M. Barnett Research Scholarship and New Investigator Award from the Heart and Stroke Foundation of Canada and Early Researcher Awards from the Ontario Ministry of Research and Innovation. A.F.R.S. is supported by the Natural Sciences and Engineering Research Council of Canada (Discovery Grant), the Canadian Institutes for Health Research (MOP-259068), and Canadian Diabetes Association (OG-3-11-3520-HC). Z.Q. and K.K. are supported by Natural Sciences and Engineering Research Council of Canada Graduate Scholarships. We thank Dr. Mary-Ellen Harper for the use of the metabolic cages and Dr. Gregory Morton for helpful discussion.

The authors declare no competing financial interests.

*T.Z. and X.Z. contributed equally to this work.

Correspondence should be addressed to either of the following: Dr. Hsiao-Huei Chen, Centre for Stroke Recovery, Ottawa Hospital Research Institute, 451 Smyth Road, Room 2422, 0ttawa, Ontario K1H 8M5, Canada, E-mail: hchen@uottawa.ca; or Dr. Alexandre Stewart, Univeristy of Ottawa Heart Institute, 40 Ruskin Road, H3100, Ottawa, Ontario K1Y 4W7, Canada, E-mail: astewart@ottawaheart.ca.

DOI:10.1523/JNEUROSCI.3419-13.2014

Copyright $\odot 2014$ the authors $\quad 0270-6474 / 14 / 340140-09 \$ 15.00 / 0$
Hrabovszky et al., 2005; Hur and Zaborszky, 2005; Stocker et al., 2006). Inhibitory inputs to the PVH evoke eating even when animals are well fed (Atasoy et al., 2012; Sternson, 2013). Thus, reduced activity of PVH neurons likely underlies hyperphagiainduced obesity, although current understanding of the mechanisms that control the firing pattern of $\mathrm{PVH}$ neurons remains incomplete.

Our previous studies revealed that mice with glutamatergic neuron-specific ablation of LIM domain only 4 (Lmo4), including all neurons of the $\mathrm{PVH}$, the majority of neurons in the $\mathrm{VMH}$, and some neurons in the dorsomedial hypothalamus (DMH), displayed metabolic defects, including diabetes and obesity (Zhou et al., 2012; Pandey et al., 2013). However, given the diverse functions ascribed to each of these hypothalamic nuclei and the complexity of the metabolic phenotype of these LMO4deficient (CamK2 $\alpha \mathrm{Cre} / \mathrm{Lmo} 4^{\text {flox/flox }}$ ) mice, LMO4 may affect multiple modalities of metabolic homeostasis.

LMO4 is a transcription cofactor, essential for CNS development (Chen et al., 2002; Hahm et al., 2004; Tse et al., 2004; Joshi et al., 2009; Duquette et al., 2010; Cederquist et al., 2013). LMO4 mediates calcium-dependent transcription in cortical neurons (Aizawa et al., 2004; Kashani et al., 2006). Our studies further showed that LMO4 regulates calcium-induced calcium release and synaptic plasticity in neurons of the hippocampus (Qin et al., 2012). Thus, several lines of evidence indicate that LMO4 is tied to the regulation of neuronal activity through calcium signaling.

To determine what LMO4 does specifically in the PVH to affect metabolic homeostasis, we ablated Lmo4 selectively in the PVH through Cre recombinase-dependent excision driven 
by the single-minded 1 (Sim1) promoter (Balthasar et al., 2005). Compared with the CamK2 $\alpha \mathrm{Cre} / \mathrm{Lmo} 4^{\text {flox/flox }}$ mice, Sim1Cre/ Lmo $4^{\text {flox/flox }}$ mice exhibit early-onset hyperphagia that progresses rapidly to obesity and insulin resistance. In contrast to the CamK $2 \alpha \mathrm{Cre} / \mathrm{Lmo} 4^{\text {flox/flox }}$ mice, insulin resistance in Sim1Cre/ $\mathrm{Lmo} 4^{\text {flox/flox }}$ mice is prevented by calorie restriction, demonstrating that the metabolic phenotype is entirely driven by hyperphagia. Electrophysiological studies showed that LMO4 is required to maintain the expression of voltage-activated $\mathrm{Ca}^{2+}$ channels to set the activity of parvocellular PVH neurons. Hyperphagia was suppressed using a pharmacogenetic approach to activate PVH neurons in Sim1Cre/Lmo $4^{\text {flox/flox }}$ mice. Collectively, our data show that by setting the basal neural activity of PVH neurons, LMO4 is critically important to control proper food intake.

\section{Materials and Methods}

All experimental protocols were approved by the University of Ottawa Animal Care and Veterinary Service and were in accordance with the institutional guidelines.

Mice. A triple transgenic Sim1Cre/Lmo $4^{\text {flox/flox} / R O S A 26-E G F P ~}$ mouse was obtained by breeding Lmo4flox mice (Schock et al., 2008; Zhou et al., 2012; Pandey et al., 2013) with the Sim1Cre (Balthasar et al., 2005) and the ROSA26-EGFP (Mao et al., 2001) mouse lines on the C57BL/6J genetic background for $>6$ generations. GFP-positive Sim1Cre cells in the PVH were visualized by immunofluorescence for patch-clamp experiments. Genotypes were determined by PCR analysis as described previously (Mao et al., 2001; Balthasar et al., 2005; Schock et al., 2008). The mice were housed at room temperature $\left(23 \pm 2^{\circ} \mathrm{C}\right)$, fed $a d$ libitum, and were maintained under a $12 \mathrm{~h}$ light/dark cycle (lights on at $0700 \mathrm{~h}$ ). In most cases, experiments were performed with male mice unless stated otherwise. For all experiments, the examiners were blinded to the genotype of the mice.

Brain slice preparation. Three- to 5-week-old Lmo4 knock-out (KO) and littermate control mice were anesthetized with isoflurane (Sigma). Caudal PVH (bregma $-1.30 \mathrm{~mm}$ to $-2.0 \mathrm{~mm}$ ) brain slices of $250 \mu \mathrm{m}$ thickness were sectioned in the coronal plane, in ice-cold carbogenequilibrated solution containing the following (in $\mathrm{mM}$ ): $2.5 \mathrm{KCl}, 10$ $\mathrm{MgSO}_{4}, 1.25 \mathrm{NaH}_{2} \mathrm{PO}_{4}, 24 \mathrm{NaHCO}_{3}, 0.5 \mathrm{CaCl}_{2}-2 \mathrm{H}_{2} \mathrm{O}, 11$ glucose, and 234 sucrose. The slices were incubated at room temperature $\left(20-24^{\circ} \mathrm{C}\right)$ in solution containing the following (in $\mathrm{mM}$ ): $124 \mathrm{NaCl}, 3 \mathrm{KCl}, 3 \mathrm{MgSO}_{4}$, $1.25 \mathrm{NaH}_{2} \mathrm{PO}_{4}, 26 \mathrm{NaHCO}_{3}, 1 \mathrm{CaCl}_{2}-2 \mathrm{H}_{2} \mathrm{O}$, and 10 glucose.

Electrophysiology. Electrophysiological experiments were performed at room temperature $\left(20-24^{\circ} \mathrm{C}\right)$, and the techniques were similar to those reported previously (Zaman et al., 2011).

Intrinsic firing properties were recorded in coronal sections containing the caudal region of the $\mathrm{PVH}$ in recording solution (in $\mathrm{mM}$ ) as follows: $124 \mathrm{NaCl}, 3 \mathrm{KCl}, 3 \mathrm{MgSO}_{4}, 1.25 \mathrm{NaH}_{2} \mathrm{PO}_{4}, 26 \mathrm{NaHCO}_{3}, 2.4$ $\mathrm{CaCl}_{2}-2 \mathrm{H}_{2} \mathrm{O}$, and 10 glucose bubbled with $95 \% \mathrm{O}_{2} / 5 \% \mathrm{CO}_{2}$. The Sim 1 neurons expressing Cre-dependent GFP marker were visualized through an upright epifluorescence microscope (Nikon FN). Recording electrodes were pulled on Narishige PC-10 from fabricated borosilicate glass capillaries (G150F-4, OD; $1.50 \mathrm{~mm}$, ID; $0.86 \mathrm{~mm}$, Warner Instruments) and had 4-6 $\mathrm{M} \Omega$ tip resistance when filled with an intracellular solution containing the following (in $\mathrm{mm}$ ): $140 \mathrm{~K}$-gluconate, $10 \mathrm{KCl}, 1 \mathrm{MgCl}_{2}, 10$ HEPES, 0.02 EGTA, $3 \mathrm{Mg}$-ATP, and $0.5 \mathrm{Na}^{2}$-GTP.

Recordings for $\mathrm{Ca}^{2+}$ currents were performed in an extracellular solution as described previously (Sun et al., 2001; Zaman et al., 2011) consisting of the following (in $\mathrm{mm}$ ): $100 \mathrm{NaCl}, 25$ tetraethyl ammonium (TEA)-Cl, $5 \mathrm{CaCl}_{2}, 20$ HEPES, $2 \mathrm{MgCl}_{2}, 5$-amino pyridine (4-AP), 10 glucose, and 0.001 TTX. Recording pipettes were filled with cesiumbased internal solution containing $130 \mathrm{~mm} \mathrm{CsCl}, 10 \mathrm{~mm}$ HEPES, $5 \mathrm{~mm}$ TEA-Cl, 10 mм EGTA, 4 mм $\mathrm{MgCl}_{2}, 4$ mм Mg-ATP, and 0.3 $\mathrm{Na}_{2}$-GTP. The currents were corrected for capacitive and leak currents.

The $\mathrm{pH}$ was adjusted to 7.35 with $\mathrm{KOH}$ and $\mathrm{CsOH}$ for current- and voltage-clamp experiments, respectively. The osmolarity was maintained to $290-300 \mathrm{mosmol} / \mathrm{L}$ with sucrose. Signals were amplified with a
Multiclamp700-B amplifier (Molecular Devices) and analyzed using pClamp10 and Mini Analysis Program (Synaptosoft).

Stereotaxic adeno-associated viruses (AAV)-designer receptors exclusively activated by designer drugs (DREADD) injections. Caudal PVH coordinates were as follows: bregma $-1.50 \mathrm{~mm}$; midline $\pm 0.25 \mathrm{~mm}$; dorsoventral $-4.90 \mathrm{~mm}$; infusion speed $=50 \mathrm{nl} / \mathrm{min}$. Tissue adhesive (3M Vetbond) was applied to promote natural healing. Postoperative analgesia was provided (Tylenol, $1 \mathrm{mg} / \mathrm{kg}$ ). The $0.3 \mu \mathrm{l}$ of AAV virus containing hM3Dq or hM4Di was injected bilaterally into caudal PVH of 6-week-old Sim1Cre/Lmo $4^{\text {flox/wt }}$ and Sim1Cre/Lmo $4^{\text {flox/flox }}$ mice. After surgery, mice were housed at standard temperature, light/dark cycle, chow and water ad libitum, and allowed 3 weeks for recovery and transgene expression.

Food intake studies in $A A V$-DREADD-injected mice. Mice were habituated to handling and the metabolic cages. Food intake studies were performed on regular chow. All mice were injected intraperitoneally with saline on the first day and with clozapine- $N$-oxide $(\mathrm{CNO})$ on the following day. For mice infected with hM3Dq, CNO was administered at 18:00 $\mathrm{h}(1 \mathrm{mg} / \mathrm{kg})$ and food intake was assessed for $2 \mathrm{~h}$. For mice infected with hM4Di, CNO was administered at 12:00 h (5 mg/kg) (Atasoy et al., 2012) and food intake was assessed for $3 \mathrm{~h}$.

Immunohistochemistry. Mice were anesthetized with $100 \mu$ l (i.p.) of a ketamine/xylazine/acepromazine (100/20/10 mg/ml) mixture. Mice were immediately perfused intracardially with PBS solution followed by $4 \%$ PFA, pH 7.4. Brains were fixed in $4 \%$ PFA, treated with $20 \%$ sucrose, and quick-frozen in isopentane at $-35^{\circ} \mathrm{C}$. The $30 \mu \mathrm{m}$ sections containing ARC and caudal PVH were made using Leica cryotome. Slides were dried at $37^{\circ} \mathrm{C}$ for $30 \mathrm{~min}$ and then blocked at room temperature for $1 \mathrm{~h}$ in $5 \%$ donkey serum containing $0.1 \%$ Triton X100. Slides were then incubated for $24 \mathrm{~h}$ at $4^{\circ} \mathrm{C}$ with primary antibodies in $1 \%$ donkey serum. Slides were then washed 5 times for $5 \mathrm{~min}$ each in PBS before incubation for $1 \mathrm{~h}$ at room temperature with secondary antibodies. The antibodies used include goat anti-LMO4 (C-15) (Santa Cruz Biotechnology; 1:200), rabbit anti-c-fos (Santa Cruz Biotechnology; 1:400), Cy2 and Cy5 (Jackson ImmunoResearch Laboratories; 1:800) secondary antibodies. Negative controls omitting the primary antibody were imaged using identical settings (data not shown).

Real-time $q R T-P C R$. Total RNA from the caudal hypothalamus containing the PVH was extracted using TRIzol reagent (Invitrogen) followed by ethanol purification, reverse-transcribed to cDNA with random decamers, and reverse-transcriptase (Ambion). An aliquot of cDNA was used for qPCR with specific primers or actin primers together with TaqDNA polymerase/SYBR Green PCR mix (New England Biolabs) with the Rotor-Gene 3000 System (Corbett Life Science). All mRNA levels were normalized to CycloA as described previously (Qin et al., 2012). Gene-specific qPCR primers used included the following: CycloA: forward, 5-GGC CGA TGA CGA GCC C-3; reverse, 5-TGT CTT TGG AAC TTT GTC TGC AAA T-3; Lmo4: forward, 5-GGA CCG CTT TCT GCT CTA TG-3; reverse, 5-AAG CAC CGC TAT TCC CAA AT-3; Cacnale: forward, 5-CCG ATG ATG ATG AGA GGG AT-3; reverse, 5-TGC TGA CTG TCT TCC AAT GC-3; Cacnal g: forward, 5-GTA GAC GAG CAG CTT CAG CA-3; reverse, 5-GGT CAA TAC CCT CAG CAT GG-3; Cacnalh: forward, 5-CTC GGT CAT GGT GGC AGA-3; reverse, 5-CCG AGG AGG CGA TAC TGG-3; Cacnali: forward, 5-CAT GAA GAC CAT GGA CAA CG-3; reverse, 5-TGT CCA TTG GGT GTC ATG G-3; Mc3R: forward, 5-GCCTGCTTATTGGCTTTGTA-3; reverse, 5-TGTAAGTTCTGGAAGGGAGC-3; Mc4R: forward, 5-GGTCGGAAACCATCGTCA-3; reverse, 5-GGAAAGCAGGCTGCAAAT-3; Mc5R: forward, 5-GGAGCAGAGCAGAATGGT-3; reverse, 5-ATGGGTGAGTGCAGGTTT-3.

Glucose and insulin tolerance test. Mice were fasted overnight $(\sim 16 \mathrm{~h})$ in fresh cages with free access to water. Tests were performed at 10:00 h. Basal blood glucose was measured before mice receiving 20\% D-glucose ( $2 \mathrm{~g} / \mathrm{kg}$ body weight, i.p.). At 15, 30, 60, and $120 \mathrm{~min}$, blood glucose was sampled from the saphenous vein using a standard glucometer (Pandey et al., 2013). Mice were fasted for $4 \mathrm{~h}$ before the insulin tolerance test. The test was performed between 14:00 and 17:00 h. Human recombinant insulin (Sigma, catalog \#91077C) diluted in sterile saline was administered by intraperitoneal injection at $0.75 \mathrm{U} / \mathrm{kg}$. Blood glucose levels were 
monitored in the same manner as described for the glucose tolerance test protocol at 4 different time points: before (T0), and 15, 30, and 60 min after insulin injection. Data were presented as percentage T0 blood glucose versus time.

Paired feeding. Mice were housed individually throughout the study (4-17 weeks). Food intake was measured in littermate control mice for 1 week as described previously (Zhou et al., 2012). In the paired-feeding experiment, Lmo4 $\mathrm{KO}$ mice and their littermate controls were provided an average amount of food consumed by age-matched control mice. Mice were fed twice daily, one-third of food was given at 9 A.M. and two-thirds at 5 P.M. to ensure that mice never underwent long periods of fasting. Body weight was measured twice a week over the pair-feeding period, after which mice were subjected to glucose tolerance or insulin tolerance tests.

Indirect calorimetry. Mice were singlehoused in metabolic chambers for $24 \mathrm{~h}$ and oxygen consumption $\left(\mathrm{VO}_{2}\right)$ and carbon dioxide production $\left(\mathrm{VCO}_{2}\right)$ were measured using an Oxymax System with automatic temperature and light controls (Columbus Instruments). Temperature was maintained at $24^{\circ} \mathrm{C}$, and lighting was on a normal $12 \mathrm{~h}$ light/dark cycle. System settings included a flow rate of 0.5 $\mathrm{L} / \mathrm{min}$, a sample line-purge time of $2 \mathrm{~min}$, and a measurement period of $60 \mathrm{~s}$ every $12 \mathrm{~min}$.

Protein-phosphatase 1B (PTP1B) phosphatase activity assay. PTP1B phosphatase activity was measured with the PhosphoSeek PTP1B Assay Kit (BioVision) in extracts from the dorsal hypothalamus (mainly $\mathrm{PVH}$ and $\mathrm{DMH}$ ) wedges according to the manufacturer's instructions with PTP1B enzyme and phosphatase inhibitor as positive and negative controls, respectively (Pandey et al., 2013).

Statistical analysis. Data acquisition, analyses, and presentation were performed using a combination of pClamp10 (Molecular Devices), the Statistical Package for the Social Sciences version 14 (SPSS), and the Sigma Plot 11 (Jandel Scientific). All data are presented as mean \pm SEM unless stated otherwise. $p$ values of $<0.05$ were considered statistically significant. Two-way ANOVA and two-tailed $t$ tests were used for comparisons, where appropriate.

\section{Results}

\section{Ablation of Lmo4 in Sim1 PVH neurons causes hyperphagia and obesity}

In the hypothalamus, Sim1 is expressed in neurons of the PVH nucleus and Sim1Cre transgenic mice expressing Cre recombinase under the control of the Sim1 promoter enable PVHselective ablation of floxed alleles (Balthasar et al., 2005). qRTPCR analysis showed that $L m o 4$ mRNA levels were reduced in the dorsal hypothalamus of Sim1Cre/Lmo $4^{\text {flox/flox }} \mathrm{KO}$ mice compared with their littermate controls (Sim1Cre/Lmo4 $4^{\text {flox/wt }}$, WT) (Fig. 1A). Absence of LMO4 in the PVH was confirmed by immunofluorescence (Fig. 1B, top). Sim 1 is also expressed in the supraoptic nucleus, the nucleus of the lateral olfactory tract, and the medial amygdala (Balthasar et al., 2005), but we did not detect LMO4 expression in these regions (data not shown). Ablation of
B
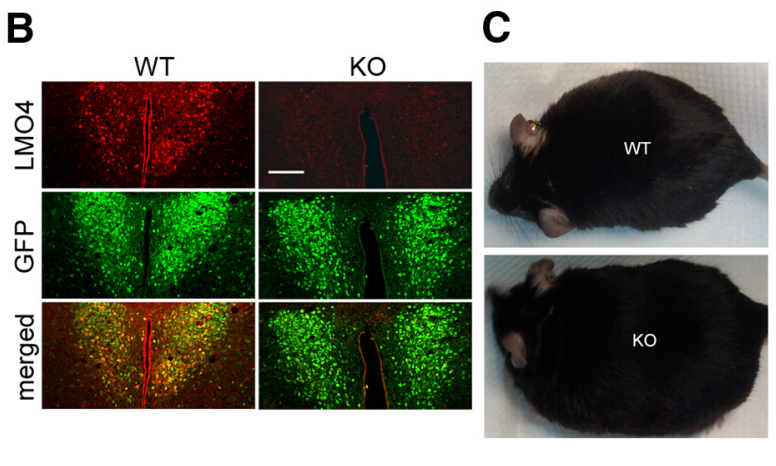

Male

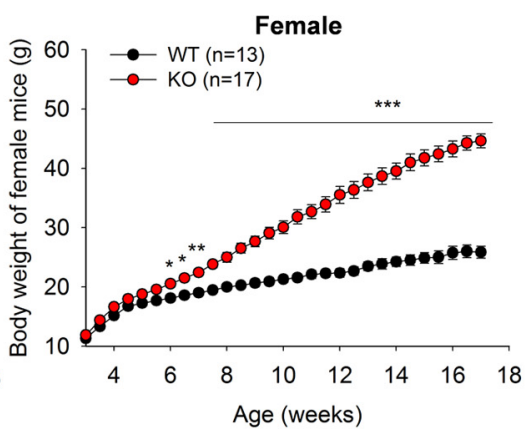

$\mathbf{F}$

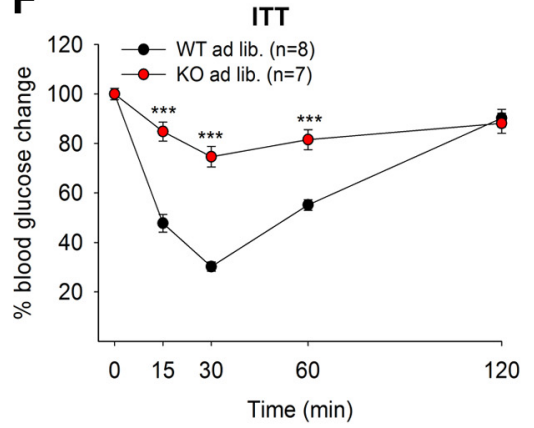

Figure 1. Lmo4 ablation in the PVH causes obesity and insulin resistance. $A$, Real-time qRT-PCR ( $n=6$ per genotype) showed reduced LM04 mRNA from hypothalamic extracts. $\boldsymbol{B}$, Immunofluorescent staining showed that LM04 (in red) is expressed in

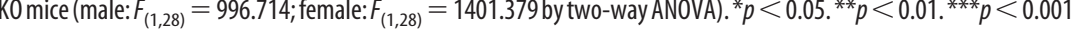
Glucose tolerance test $(\boldsymbol{E})$ and insulin tolerance test $(\boldsymbol{F})$ at 3 months. Data are mean \pm SEM. ${ }^{*} p<0.05$ (Student's two-tailed $t$ test). ${ }^{* *} p<0.01$ (Student's two-tailed $t$ test). ${ }^{* * *} p<0.001$ (Student's two-tailed $t$ test).

LMO4 did not reduce the number of Sim1-positive PVH neurons (Fig. $1 B$, bottom). Sim1Cre/Lmo $4^{\text {flox/flox }}$ mice are morbidly obese even when fed regular chow (Fig. 1C). The early-onset obesity started at 5 weeks ( 2 weeks after weaning) and was observed in both male and female mice (Fig. 1D). By 3 months of age, mice had impaired glucose homeostasis (Fig. 1E) and were insulin resistant (Fig. $1 F$ ). No change in locomotor activity (Fig. $2 A$ ) or energy expenditure (Fig. $2 B$ ) was observed at 5 weeks of age (the onset of weight gain). Instead, increased body weight was associated with hyperphagia detected as early as 5 weeks of age (Fig. 2C). To test whether increased food consumption is the result of increased hedonic behavior (i.e., the pleasure of eating), we conducted a sugar preference test. Lmo4 KO mice consumed as much sugar water as littermate controls (Fig. $2 D$ ), suggesting that aberrant hedonic behavior is unlikely to be the cause of hyperphagia. It is also worth noting that qPCR analysis showed no change in the hypothalamic mRNA levels 
A

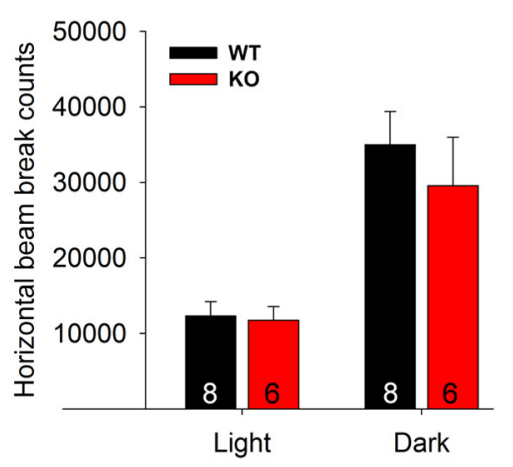

D

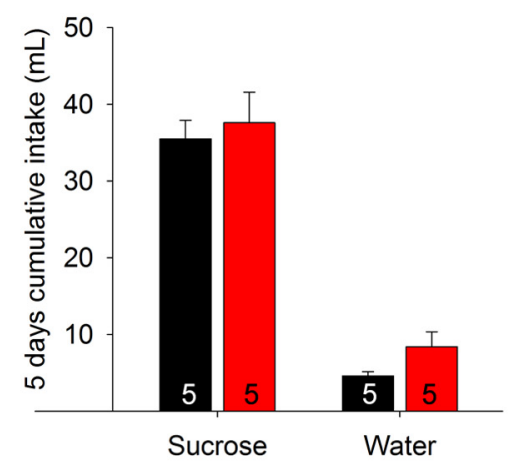

G

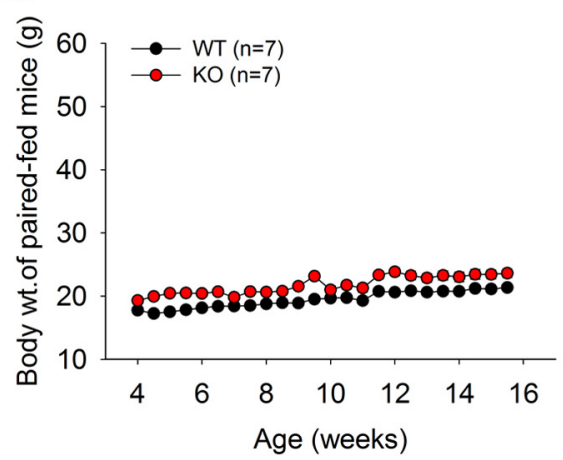

B

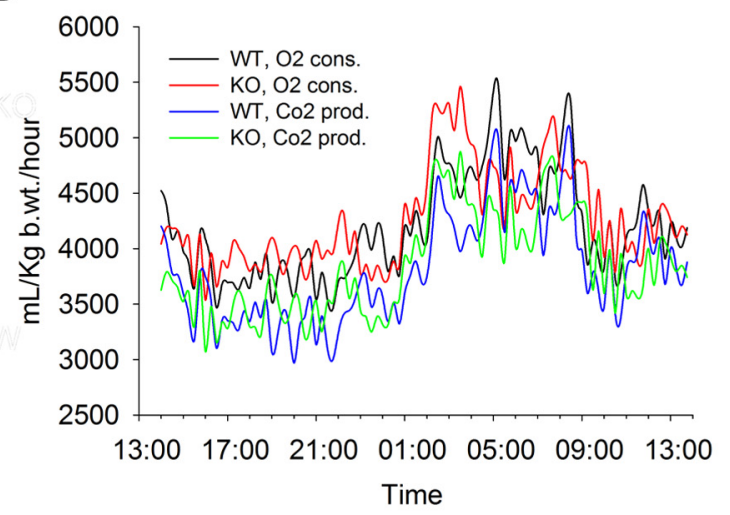

C

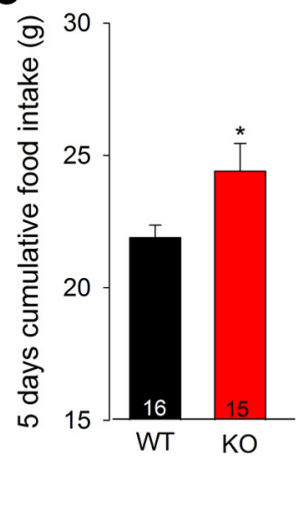

E

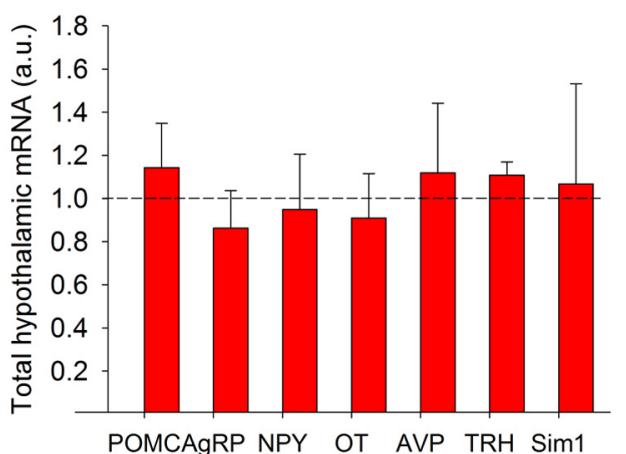

H

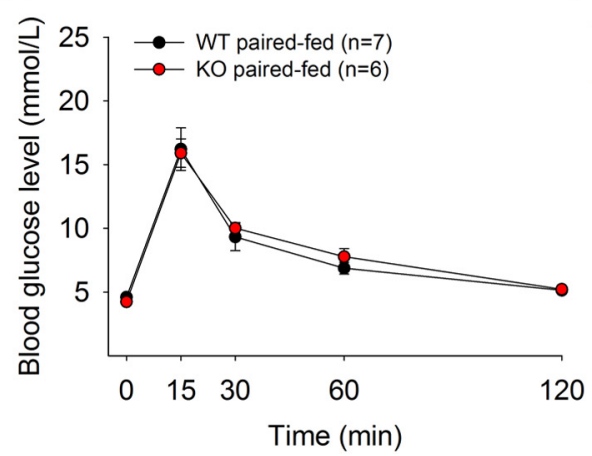

$\mathbf{F}$

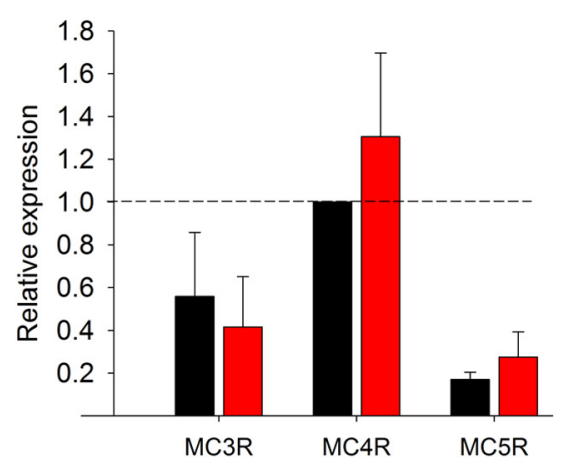

I

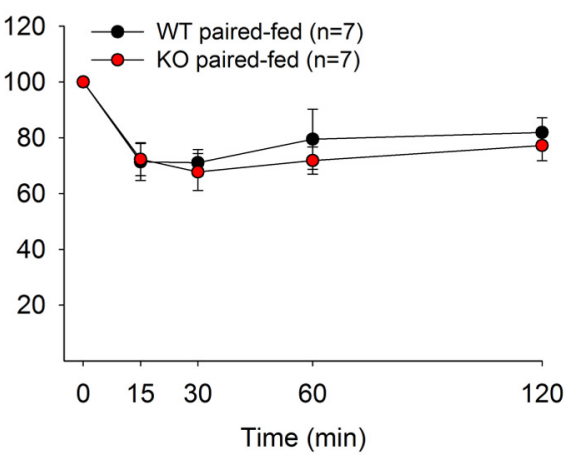

Figure 2. Hyperphagia accounts for metabolic phenotypes in mice with Lmo4 ablation in the PVH. $\boldsymbol{A}$, Beam-break counts for locomotor activity. $\boldsymbol{B}$, Energy expenditure measured by oxygen consumption and $\mathrm{CO}_{2}$ production ( $n=8 \mathrm{WT}$ and $6 \mathrm{KO}$ male mice). $\boldsymbol{C}$, Food intake $>5 \mathrm{~d}$. D, Sucrose preference test. Mice were offered the choice between water and water with $1 \%$ sucrose for the test. qRT-PCR of hypothalamic mRNAs shows no difference in the expression levels of $(\boldsymbol{E}) \operatorname{Sim} 1$ and various neurotransmitters and $(\boldsymbol{F})$ melanocortin receptors. $n=6$ male K0 and 6 male littermate control (WT) mice. Body weight progression $(\boldsymbol{G})$, glucose tolerance test $(\boldsymbol{H})$, and insulin tolerance test $(\boldsymbol{I})$ under calorie-restricted paired-feeding in female mice. All the measurements were done at 5 weeks of age, except for paired-feeding. Data are mean \pm SEM. ${ }^{*} p<0.05$ (Student's two-tailed $t$ test). P0MC, Pro-opiomelanocortin; AgRP, Agouti-related protein; NPY, neuropeptide Y; 0T, oxytocin; AVP, arginine vasopressin; TRH, thyrotropin releasing hormone.

of neuropeptides, including Agouti-related protein, neuropeptide $\mathrm{Y}$, pro-opiomelanocortin, oxytocin, vasopressin, and thyrotropin releasing hormone in the Lmo4 KO PVH (Fig. 2E). Also of note, mRNA levels of Sim 1 were not affected by Lmo4 ablation (Fig. 2E). Similarly, mRNA levels for melanocortin receptors that mediate the satiety response to $\alpha \mathrm{MSH}$ were not different in the Lmo4 KO PVH (Fig. 2F).

To determine whether obesity and diabetes are the result of increased food intake, we matched the caloric intake of $L m o 4 \mathrm{KO}$ mice with littermate controls. Paired-feeding normalized body weight progression (Fig. 2G) and prevented glucose intolerance (Fig. $2 \mathrm{H}$ ) and insulin resistance (Fig. 2I), confirming that the lack of LMO4 in the PVH caused obesity and diabetes entirely through hyperphagia.
Lmo4-ablated Sim1 PVH neurons have reduced activity

Using patch-clamp recording, we compared neuronal activity in Siml neurons of the caudal PVH in Lmo4 KO and littermate control mice. To visualize Sim1 neurons, Sim1Cre/Lmo 4 flox/flox mice were bred with ROSA26-EGFP mice allowing enhanced GFP expression in Sim1 neurons that express Cre-recombinase (Fig. 3A). Spontaneous firing was much reduced in Lmo4 KO mice compared with littermate controls (Fig. 3 B, C), despite similar resting membrane potentials (Table 1 ). Reduced spontaneous firing could result from increased inhibitory inputs, reduced excitatory inputs, or a cell-intrinsic reduction in excitability resulting from altered expression of membrane channels. Membrane resistance was significantly elevated (by 50\%) in Lmo4-ablated neurons (Table 1), indicating that 
fewer membrane channels are present in Lmo4 KO PVH neurons. Of note, membrane capacitance (a measure of cell size) was not different between $\mathrm{Lmo} 4 \mathrm{KO}$ and littermate control PVH neurons.

To determine whether calcium currents are affected in $\mathrm{Lmo} 4 \mathrm{KO} \mathrm{PVH}$ neurons and might account for the reduced excitability, we examined low-threshold spiking (LTS) and tonic firing, two properties closely tied to the low-voltage-activated (LVA) and high-voltage-activated (HVA) calcium channels, respectively. LTS was evoked by a hyperpolarizing current injection (Sun et al., 2001; Zaman et al., 2011). Under current-clamp mode, releasing a hyperpolarizing current generates LTS by allowing LVA Ca ${ }^{2+}$ channels to recover from inactivation (Suzuki and Rogawski, 1989). LTS was detected in $78.5 \%$ of littermate control PVH neurons ( $n=15$ of 19$)$, whereas $\sim 21 \%$ ( $n=4$ of 19 ) of the cells exhibited no LTS (Fig. 3D,E), as reported previously for parvocellular neurons of the caudal PVH (Luther et al., 2002). In contrast, only 12\% of GFP-positive LMO4-deficient neurons ( $n=3$ of 26) exhibited LTS (Fig. 3D,E).

Tonic firing was induced by injecting depolarizing currents in $10 \mathrm{pA}$ stepwise increments ( 10 steps, $1 \mathrm{~s}$ duration) from a holding potential of $-50 \mathrm{mV}$. Increased tonic spike frequency was observed with each increment of injected current. However, a much lower response was observed in Lmo4 KO neurons (Fig. $3 F, G$ ). Thus, ablation of Lmo4 in PVH neurons likely decreases the expression of both low- and high-voltage-gated calcium channels, and these would reduce spontaneous firing and cell excitability as we observed in Lmo4-ablated PVH neurons.

Reduced low- and high-voltage-gated $\mathrm{Ca}^{2+}$ currents in Lmo4 KO PVH neurons

$\mathrm{Ca}^{2+}$ channels play a critical role in neuronal excitability (Perez-Reyes, 2003). The markedly reduced LTS we observed in LMO4-deficient PVH neurons (Fig. $3 D, E$ ) led us to examine the status of LVA Ca ${ }^{2+}$ currents. We measured LVA currents in $\mathrm{Cs}^{+}$-based whole-cell patch clamping as described previously (Sun et al., 2001). Neurons were held at $-100 \mathrm{mV}$ ( $1 \mathrm{~s}$ ) and depolarized to $-40 \mathrm{mV}$, below the activation threshold for HVA Ca ${ }^{2+}$ channels. This depolarization step induces a fast-inactivating T-type $\mathrm{Ca}^{2+}$ current (Fox et al., 1987). We observed a significant reduction in peak current density of $\mathrm{Ca}^{2+}$ in LMO4-deficient PVH neurons $(-1.60 \pm 0.45$ $\mathrm{pApF}^{-1}[n=12]$ in $\mathrm{KO}$ vs $-7.28 \pm 2.01 \mathrm{pApF}^{-1}[n=18]$ in WT; $p>0.05$; Fig. $4 A, B)$.

In addition, the reduced tonic firing frequency we observed in response to depolarizing inputs (Fig. $4 F, G$ ) suggests that HVA $\mathrm{Ca}^{2+}$ channels may also be altered. To test this possibility, an inward current was evoked by depolarizing voltage steps from a holding potential of $-50 \mathrm{mV}$ to test potentials between -50 to 30 $\mathrm{mV}$ (Sun et al., 2001; Zaman et al., 2011). Most LVA Ca ${ }^{2+}$ chan-
B

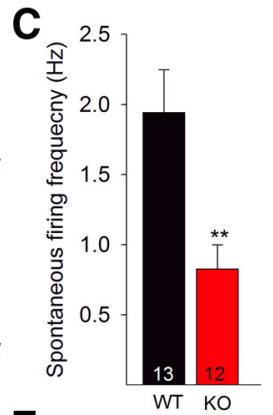

E

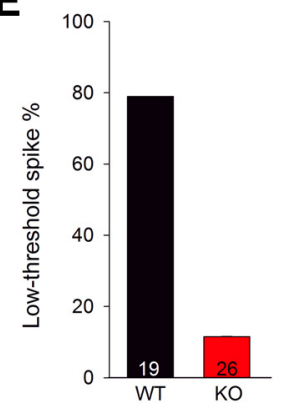

G

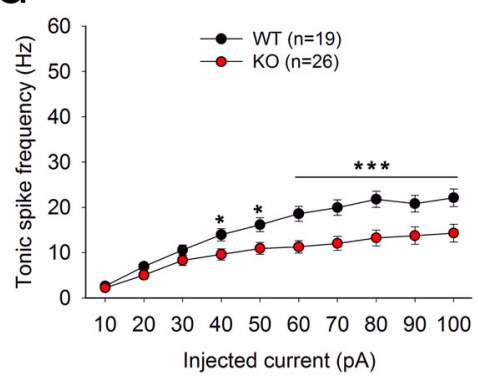

Figure 3. Neuronal activity of LM04-deficient Sim 1 neurons is reduced. A, GFP-positive neurons of the PVH (dashed oval, area recorded). Scale bar, $100 \mu \mathrm{m}$. B, Representative traces showing spontaneous firing. $\boldsymbol{C}$, Lmo $4 \mathrm{KO}$ neurons have a lower spontaneous firing frequency than their littermate controls (WT). D, Representative traces show low-threshold spiking (LTS) in Lm04 K0 and traces showing neuronal activity in response to depolarizing currents $(20,40$, and $60 \mathrm{pA})$ from $-50 \mathrm{mV}$ of holding potential. G, Tonic spike frequency in response to various depolarizing currents presented as mean $\pm S E M, F_{(1,9)}=64.90$; two-way ANOVA: ${ }^{*} p<0.05 ;{ }^{* *} p<0.01 ;{ }^{* * *} p<0.001$

Table 1. Membrane properties of Sim1 GFP-positive parvocellular neurons of the PVH

\begin{tabular}{llll}
\hline Genotype of neurons & $\mathrm{Cm}(\mathrm{pF})$ & $\mathrm{Rm}(\mathrm{m} \Omega)$ & $\mathrm{RMP}(\mathrm{mV})$ \\
\hline WT $(N=18)^{a}$ & $35.25 \pm 1.97$ & $491.57 \pm 48.61$ & $-54.22 \pm 1.34$ \\
${\text { Lmo4 KO }(N=23)^{b}}_{p \text { value }}^{30.91 \pm 1.22}$ & $735.62 \pm 83.88$ & $-54.22 \pm 1.04$ \\
\hline
\end{tabular}

$\mathrm{Cm}$, Membrane capacitance; Rm, membrane resistance; RMP, resting membrane potential.

${ }^{a}$ Cells from *7 littermate control (WT) mice.

${ }^{b}$ Cells from 9 Lmo4 KO mice.

nels should stay inactivated under these conditions. The peak current density in $L m o 4 \mathrm{KO}(-8.33 \pm 2.13,-13.25 \pm 1.57$, and $\left.-14.97 \pm 1.21 \mathrm{pApF}^{-1} ; n=19\right)$ compared with WT $(-19.28 \pm$ $2.29,-22.34 \pm 1.54$, and $\left.-22.53 \pm 1.61 \mathrm{pApF}^{-1} ; n=22\right) \operatorname{Sim} 1$ neurons was significantly reduced at test potentials of $-10 \mathrm{mV}$ $(p<0.001), 0 \mathrm{mV}(p<0.001)$, and $10 \mathrm{mV}(p<0.001)$, respectively (Figure $3 A, C$ ).

To further examine which component of HVA $\mathrm{Ca}^{2+}$ current was affected in these neurons, we isolated nifedipine-sensitive 
A

LVA Ca ${ }^{2+}$ current

WT
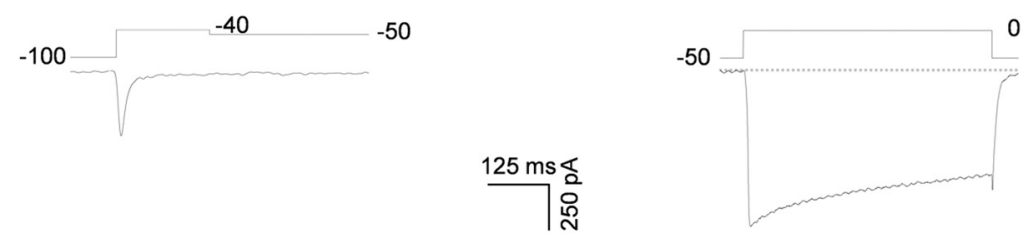

$\mathrm{KO}$

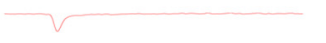

B

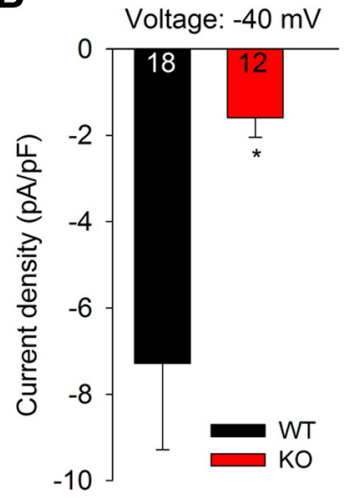

\section{C}

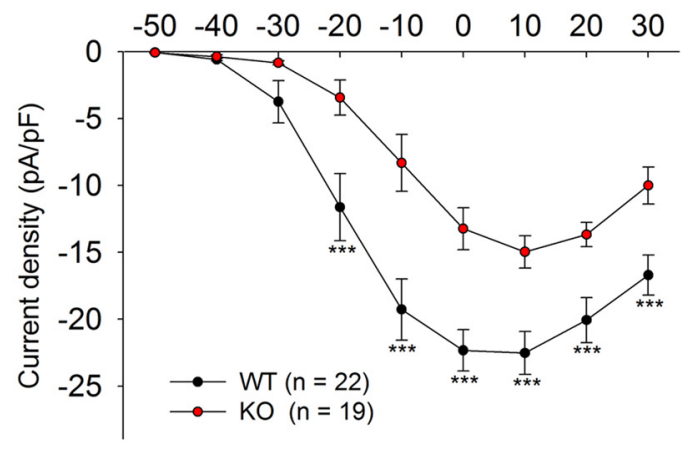

Figure 4. Total calcium current is reduced in LMO4-deficient Sim1 neurons of the PVH. A, Left, Representative traces of LVA Ca ${ }^{2+}$ currents elicited by depolarizing voltagestepsfrom $-100 \mathrm{mV}$ to atestpotential of $-40 \mathrm{mV}$ for 1 sin littermatecontrol (WT) and Lm04KOPVHneurons. Right, $\mathrm{HVA} \mathrm{Ca}^{2+}$ currents elicited by depolarizing steps from a holding potential of $-50 \mathrm{mV}$ to a test potential of $0 \mathrm{mV}$ for $1 \mathrm{~s}$. $\boldsymbol{B}$, Normalized LVA $\mathrm{Ca}^{2+}$ current at the test potential $-40 \mathrm{mV}$. C, I-V curves for HVACa ${ }^{2+}$ currents measured from the peak amplitudes (WT: $n=22$ cells, 7 mice; $\mathrm{KO}$ : $n=19$ cells, 6 mice). Data are mean \pm SEM. $F_{(1,8)}=80.38$ by two-way ANOVA: ${ }^{*} p<0.05 ;{ }^{* * *} p<0.001$.

A

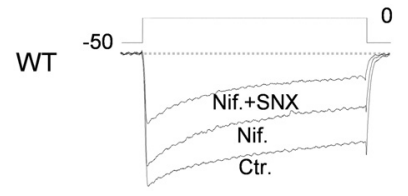

B

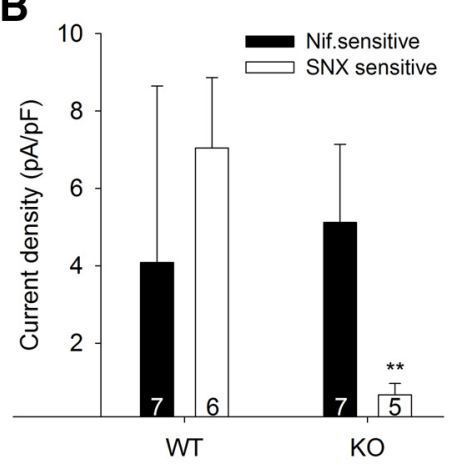

$\mathrm{KO}$

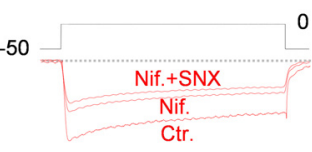

$125 \mathrm{~ms} \frac{\pi}{0}$

C

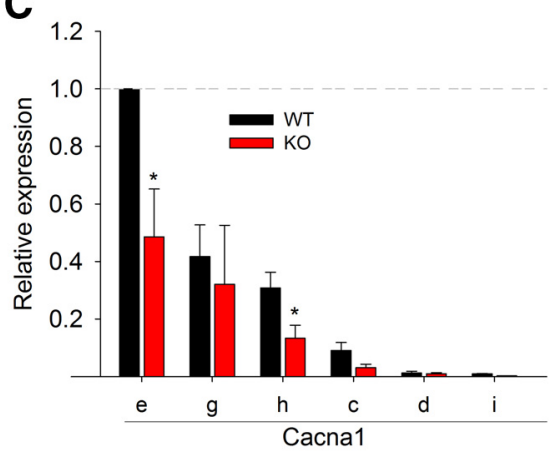

Figure 5. R-type component of $\mathrm{HVACa}^{2+}$ currents is significantly reduced in LMO4-deficient PVH neurons. $A$, Representative traces showing $\mathrm{HVACa}^{2+}$ currents elicited by depolarizing voltagesteps from $-50 \mathrm{mV}$ to a test potential of $0 \mathrm{mV}$ for $1 \mathrm{~s} . \boldsymbol{B}$, Peak current density of littermate control (WT) and Lmo4 KO PVH neurons under different experimental conditions: Ctr., Control; Nif., nifedipine $10 \mu \mathrm{M}$; +SNX, SNX-482. Data are mean \pm SEM. ${ }^{* *} p<0.01$ (Student's two-tailed $t$ test). C, Real-time qRT-PCR of mRNAs for different $\alpha$-subunits of voltage-activated $\mathrm{Ca}^{2+}$ channels in GFP-positive PVH neurons from 5-week-old mice. Data are mean \pm SEM. ${ }^{*} p<0.05$ (Student's two-tailed $t$ test).

L-type and SNX-482-sensitive R-type $(\alpha 1 \mathrm{E}) \mathrm{Ca}^{2+}$ components, currents that contribute the larger fraction of extracellular $\mathrm{Ca}^{2+}$ influx (Tsien, 1983; Perez-Reyes, 2003). Comparative analysis showed that the SNX-482-sensitive $\mathrm{Ca}^{2+}$ component was signif-
HVA Ca ${ }^{2+}$ current

icantly reduced in $\mathrm{LMO} 4$-deficient $\mathrm{PVH}$ neurons at a test potential of $0 \mathrm{mV}$ (WT, $-7.043 \pm 1.82 \mathrm{pApF}^{-1}$ vs $\mathrm{KO},-0.67 \pm$ $0.29 \mathrm{pApF}^{-1} ; p<0.01$; Fig. $\left.5 A, B\right)$.

Our recent findings suggest that LMO4 is a metabolic responsive inhibitor of PTP1B (Pandey et al., 2013). In light of this finding, we asked whether ablation of Lmo4 alters PTP1B activity in the PVH and thereby affects $\mathrm{Ca}^{2+}$ currents. Surprisingly, no significant change in $\mathrm{PTP} 1 \mathrm{~B}$ activity was detected in $\mathrm{Lmo}_{\mathrm{H}} \mathrm{KO} \mathrm{PVH}$ (data not shown) and pharmacological blockade of PTP1B by trodusquemine (10 $\mu \mathrm{M}$ ) (Lantz et al., 2010) had no effect on $\mathrm{Ca}^{2+}$ currents in LMO4-deficient neurons (data not shown), suggesting that LMO4 likely regulates calcium channels at the transcriptional rather than the posttranscriptional level. This result also suggests that PTP1B does not affect the activity of these $\mathrm{Ca}^{2+}$ channels.

Given the role of LMO4 as a transcriptional cofactor (Kashani et al., 2006), we examined whether the expression of genes encoding the $\mathrm{Ca}^{2+}$ channel $\alpha$ subunit is affected by ablation of Lmo4 by realtime qRT-PCR using mRNA purified from the cadual PVH. We found that mRNA of Cacnale and Cacnalh, $\alpha$ subunits of R-type and T-type low-voltage calcium channels, respectively, were significantly reduced in $\mathrm{Lmo} 4 \mathrm{KO} \mathrm{PVH}$ neurons (Fig. 5C), confirming that LMO4 is required for the normal expression of voltage-activated $\mathrm{Ca}^{2+}$ channels to maintain the cellular excitability of PVH neurons.

\section{Pharmacogenetic activation or suppression of PVH neuronal activity oppositely affects food intake} Increased food intake associated with reduced basal cellular excitability in PVH neurons of $\mathrm{KO}$ mice led us to postulate whether directly modulating PVH activity in vivo might alter feeding behavior. This was achieved using a pharmacogenetic approach: DREADD (Alexander et al., 2009). AAV expressing either the silencer $\mathrm{G} \alpha \mathrm{i}$ protein-coupled receptor (hM4Di) or the activator $\mathrm{G} \alpha \mathrm{q}$ protein-coupled receptor (hM3Dq) were injected stereotactically and bilaterally into the caudal PVH of 6-week-old mice (Fig. 6A) and subsequently activated by the designer drug (i.e., the pharmacologically inert ligand) CNO.

Reduced PVH activity in WT mice (Sim1-Cre/Lmo4 ${ }^{\text {flox/wt }}$ ) with the silencer hM4Di significantly increased food intake $3 \mathrm{~h}$ after $\mathrm{CNO}$ administration $(5 \mathrm{mg} / \mathrm{kg}$ i.p.) (Atasoy et al., 2012) compared with saline treatment $(0.22 \pm$ $0.04 \mathrm{~g}$ in saline vs $0.58 \pm 0.03 \mathrm{~g}$ in $\mathrm{CNO} ; n=6 ; p<0.0001$; Fig. 
$6 B)$. The increase in food intake was observed during the light period, when mice normally refrain from eating. Conversely, increasing PVH activity with the activator hM3Dq suppressed food intake in WT mice over a $2 \mathrm{~h}$ period after $\mathrm{CNO}$ administration $(1 \mathrm{mg} / \mathrm{kg}$ i.p. $)(0.72 \pm 0.03 \mathrm{~g}$ in saline vs $0.38 \pm 0.08 \mathrm{~g}$ in $\mathrm{CNO} ; n=6 ; p=$ 0.005; Fig. 6C). The reduction in food intake was observed during the dark period, when most food intake normally occurs.

Last, we tested whether pharmacogenetic activation of the PVH could override the hyperphagic effect of Lmo4 deletion. $\mathrm{CNO}$-induced depolarization is thought to occur through its inhibition of $\mathrm{M}$ current carried by PIP2-gated KCNQ channels (Biervert et al., 1998; Wang et al., 1998), a slowly inactivating, outwardly rectifying potassium current important for depression of neuronal excitability (Brown and Yu, 2000). Indeed, the activator $\mathrm{hM} 3 \mathrm{Dq}$ suppressed food intake in Lmo4 KO mice to the same degree as was observed in littermate control mice (Fig. 6C). Immunostaining for the immediate early gene c-fos confirmed the precision of virus injection and that $\mathrm{CNO}$ administration specifically activated PVH neurons (Fig. 6D). Thus, these results show that maintaining neuronal excitability in the $\mathrm{PVH}$ is required to suppress food intake. In summary, our findings indicate that LMO4 is critical for the normal expression of voltage-activated $\mathrm{Ca}^{2+}$ channels required for cellular excitability underlying homeostatic regulation of appetite.

\section{Discussion}

In this study, we have identified an essential role for LMO4 in maintaining neuronal activity of the PVH to control feeding behavior. We have shown that the lack of LMO4 in PVH neurons impairs normal activity and the normal expression of voltageactivated $\mathrm{Ca}^{2+}$ channels required for neuronal activity. Consequently, reduced activity of the PVH profoundly increases body weight resulting from hyperphagia. In addition, pharmacogenetic inactivation of PVH neurons induced hyperphagia in WT mice, whereas their pharmacogenetic activation blocked the hyperphagic phenotype of Lmo4 KO mice.

A recent study elegantly demonstrated that inhibitory input from orexigenic AgRP neurons to the PVH neurons, particularly parvocellular oxytocin neurons, increases acute feeding behavior (Atasoy et al., 2012). This study also showed that suppressing the activity of PVH Sim 1 neurons using the same pharmacogenetic approach (Sim1Cre and hMD4i) that we used here could effectively trigger acute feeding behavior. It is important to note that we observed no change in the mRNA levels of hypothalamic neuropeptides, including, AgRP, NPY, POMC, oxytocin, vasopressin, and TRH. Thus, the chronic hyperphagia we observe in Sim1Cre/Lmo $4{ }^{\text {flox/flox }}$ mice cannot be explained from altered upstream signaling from the ARC. In addition, because Sim 1 is not expressed in other brain regions that have been implicated in feeding behavior, like the VMH and DMH nuclei where LMO4

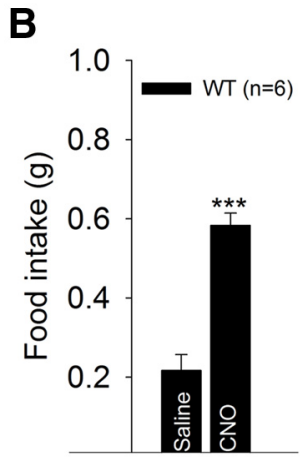

Sim1-hM4Di

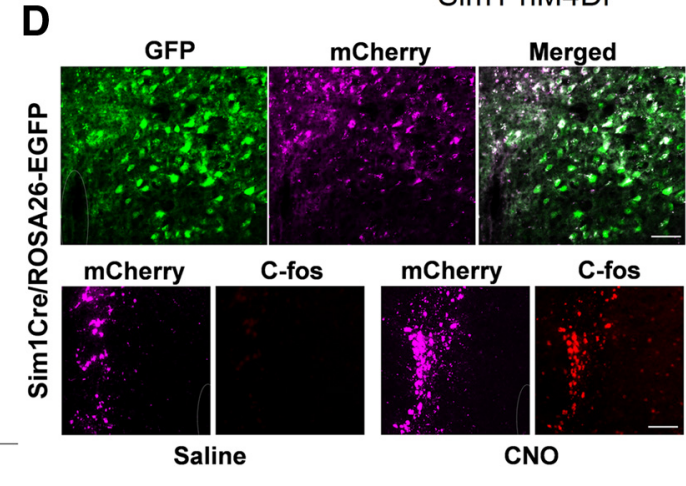

Pharmacogenetic silencing and activation of Sim 1 neurons modulate food intake in opposite directions. $\boldsymbol{A}$, Schematic indicating stereotaxic injection of (re-inducible AAV-hM3Dq-mCherry (activator) and AAV-hM4Di-mCherry (inhibitor) Cherry-injected littermate control (WT, Sim1Cre/Lmo $4^{\text {flox/wt }} /$ ROSA-EGFP, $n=6$ ). C, Food intake was suppressed $2 \mathrm{~h}$ after CNO ROSA26-EGFP mice. Scale bar, bottom: $75 \mu \mathrm{m}$.

expression remains unaffected in Sim1-Cre mice (data not shown), the selective loss of Lmo4 in Sim1 neurons of the PVH is highly likely to account for the observed phenotype of hyperphagia. Both spontaneous activity and excitability (LTS) of the Sim1 $\mathrm{PVH}$ neurons were significantly reduced in Lmo4 $\mathrm{KO}$ mice as early as 3 weeks. Consistent with this notion, pharmacogenetic activation of Sim1 neurons with AAV-hMD3q acutely suppressed food intake in WT Sim1Cre mice during the dark cycle, when mice are hungry and AgRP neurons are normally activated. The fact that we were able to suppress food intake in adult $\mathrm{Lmo}_{4}$ $\mathrm{KO}\left(\mathrm{Sim} 1 \mathrm{Cre} / \mathrm{Lmo} 4^{\text {flox/flox }}\right)$ mice at 9 weeks of age to the same extent as in WT Sim1Cre mice further strengthens our conclusion that hyperphagia in Lmo4 KO mice results from loss of Sim 1 neuron excitability. This is not the result of reduced Sim 1 expression, as revealed by qPCR, or loss of Sim1-positive neurons, as revealed by GFP immunofluorescence, or cellular atrophy because a similar membrane capacitance (an index of cell size) was observed in Lmo4 KO PVH neurons. In addition, that feeding suppression was restored by activating $\operatorname{Sim} 1$ neurons argues that Siml neurons of the PVH and their projections remain intact despite the loss of LMO4. These observations strongly indicate a role for LMO4 in maintaining the activity of Sim1 PVH neurons to prevent excess food intake.

Reduced excitability in $\mathrm{Lmo} 4 \mathrm{KO} \mathrm{PVH}$ neurons was associated with reduced expression of R-type and T-type channels. Parvo- 
cellular nonsecretory neurons of the posterior PVH respond to release from a hyperpolarizing current-clamp with LTS through T-type calcium channels (Luther et al., 2002). Among lowvoltage-activated T-type $\mathrm{Ca}^{2+}$ channels, Cacnal $i$ was barely detectable, Cacnalg expression was unchanged, and only Cacnalh was significantly reduced by $L m o 4$ ablation. In addition, expression of the intermediate-voltage-activated R-type channel Cacnale mRNA was also reduced with Lmo4 ablation. Little is known about the transcriptional regulation of Cacnale. Cacnalh can be induced by the transcription factor Egr1 (van Loo et al., 2012). It remains to be seen whether LMO4 directly modulates Egr1-dependent activation of Cacnalh.

The phenotype of Sim1Cre/Lmo $4^{\text {flox/flox }}$ mice is less complex than that of CamK $2 \alpha \mathrm{Cre} / \mathrm{Lmo} 4^{\text {flox/flox }}$ mice. The early-onset obesity observed in Sim1Cre/Lmo $4^{\text {flox/flox }}$ mice contrasts with the late-onset obesity we observed in CamK2 $\alpha \mathrm{Cre} / \mathrm{Lmo} 4^{\text {flox/flox }}$ mice (Zhou et al., 2012). In the latter model, Lmo4 was ablated in glutamatergic neurons that make up all of the neurons of the $\mathrm{PVH}$, most of the VMH, and some of the DMH (Bailey et al., 2003; Xu and Tong, 2011). Thus, we were surprised by the early voracious appetite of SimlCre/Lmo $4^{\text {flox/flox }}$ mice because no other hypothalamic nuclei other than the PVH are affected in these mice. The obesity and diabetes phenotypes could be prevented by calorie restriction through paired feeding, indicating that the metabolic phenotype was entirely the result of overeating. In contrast, paired feeding only prevented obesity but did not rescue the diabetes phenotype of CamK $2 \alpha \mathrm{Cre} / \mathrm{Lmo} 4^{\text {flox/flox }}$ mice (Pandey et al., 2013). CamK $2 \alpha \mathrm{Cre} / \mathrm{Lmo} 4^{\text {flox/flox }}$ mice are defective in central leptin signaling in the $\mathrm{VMH}$ and $\mathrm{DMH}$ and consequently have impaired glucose homeostasis and reduced sympathetic outflow to peripheral tissues, respectively. Reduced sympathetic outflow was found to affect peripheral insulin sensitivity, insulin secretion from the pancreas, lipid metabolism, and blood pressure (Zhou et al., 2012; Pandey et al., 2013). Whereas CamK $2 \alpha \mathrm{Cre} / \mathrm{Lmo} 4^{\text {flox/flox }}$ mice had reduced systolic and diastolic blood pressures (Pandey et al., 2013), Sim1Cre/Lmo $4^{\text {flox/flox }}$ mice had normal blood pressures, even when they were morbidly obese (data not shown).

It is noteworthy that the response of PVH neurons to leptin signaling (i.e., a suppression of spontaneous firing frequency that was reported previously; Ghamari-Langroudi et al., 2011) was not affected by ablation of Lmo4 in Sim1Cre/Lmo4flox mice (data not shown). This result contrasts with the loss of leptin signaling we noted in the VMH and DMH of CamK $2 \alpha$ Cre/ Lmo4 ${ }^{\text {flox/flox }}$ mice (Zhou et al., 2012; Pandey et al., 2013) and indicates that the effect of leptin to reduce spontaneous firing in $\mathrm{PVH}$ neurons is not affected by LMO4 deficiency and may involve a Jak/Stat3-independent signaling mechanism.

If $L m o 4$ was ablated in the PVH of CamK $2 \alpha \mathrm{Cre} / \mathrm{Lmo} 4^{\text {flox/flox }}$ mice, then why do they not develop hyperphagia early on as do the Sim 1 Cre/Lmo $4^{\text {flox/flox }}$ mice? One possibility may relate to an attenuating effect of the ablation of Lmo4 in the glutamatergic neurons of the DMH in CamK $2 \alpha$ Cre/Lmo $4^{\text {flox/flox }}$ mice. DMH neurons project to orexin neurons that increase feeding and energy expenditure (Stotz-Potter et al., 1996; Sakurai et al., 2005). Thus, ablation of $\mathrm{Lmo} 4$ in the glutamatergic population of the DMH might reduce feeding and counteract the hyperphagic effect of Lmo4 ablation in the PVH.

A mutation that disrupts Sim 1 causes hyperphagia and obesity in humans (Holder et al., 2000), and a study of mice with Sim1 haploinsufficiency revealed that loss of oxytocin signaling from the PVH accounted for the severe hyperphagia (Kublaoui et al., 2008). Loss of function of oxytocin neurons in the PVH has been linked to Prader-Willi syndrome, a neurological disorder associated with voracious appetite and obesity (Swaab et al., 1995). It will be interesting to see whether the Prader-Willi syndrome affects LMO4 expression in PVH neurons. Our study reveals that LMO4 plays a central role in establishing caudal Sim1 PVH neuron excitability through modulation of voltage-gated $\mathrm{Ca}^{2+}$ channels and that Sim1 neuron-specific ablation of Lmo4 during development causes hyperphagia. It remains to be seen whether ablation of Lmo4 after birth or in adulthood would have a similar effect on feeding behavior. A recent study showed that activation of oxytocin neurons, a subset of Sim 1 neurons of the caudal PVH, strongly suppresses feeding behavior (Atasoy et al., 2012). We suspect that the main hyperphagic effect of $L m o 4$ ablation occurs by disrupting excitability of oxytocin neurons. However, a recent study noted that ablated oxytocin neurons in adult mice did not cause hyperphagia but rather affected energy expenditure (Wu et al., 2012). In addition to oxytocin neurons, other PVH neurons like those expressing arginine vasopressin might be responsible for the control of feeding behavior (Aoyagi et al., 2009). Future studies using an oxytocin or arginine vasopressin promoter-Cre transgenic mouse will be required to address whether LMO4 is required for oxytocin or arginine vasopressin neuron-dependent control of feeding behavior.

\section{References}

Aizawa H, Hu SC, Bobb K, Balakrishnan K, Ince G, Gurevich I, Cowan M, Ghosh A (2004) Dendrite development regulated by CREST, a calciumregulated transcriptional activator. Science 303:197-202. CrossRef Medline

Alexander GM, Rogan SC, Abbas AI, Armbruster BN, Pei Y, Allen JA, Nonneman RJ, Hartmann J, Moy SS, Nicolelis MA, McNamara JO, Roth BL (2009) Remote control of neuronal activity in transgenic mice expressing evolved G protein-coupled receptors. Neuron 63:27-39. CrossRef Medline

Aoyagi T, Kusakawa S, Sanbe A, Hiroyama M, Fujiwara Y, Yamauchi J, Tanoue A (2009) Enhanced effect of neuropeptide $Y$ on food intake caused by blockade of the $\mathrm{V}(1 \mathrm{~A})$ vasopressin receptor. Eur J Pharmacol 622:32-36. CrossRef Medline

Atasoy D, Betley JN, Su HH, Sternson SM (2012) Deconstruction of a neural circuit for hunger. Nature 488:172-177. CrossRef Medline

Bailey TW, Nicol GD, Schild JH, DiMicco JA (2003) Synaptic and membrane properties of neurons in the dorsomedial hypothalamus. Brain Res 985:150-162. CrossRef Medline

Balthasar N, Dalgaard LT, Lee CE, Yu J, Funahashi H, Williams T, Ferreira M, Tang V, McGovern RA, Kenny CD, Christiansen LM, Edelstein E, Choi B, Boss O, Aschkenasi C, Zhang CY, Mountjoy K, Kishi T, Elmquist JK, Lowell BB (2005) Divergence of melanocortin pathways in the control of food intake and energy expenditure. Cell 123:493-505. CrossRef Medline

Biervert C, Schroeder BC, Kubisch C, Berkovic SF, Propping P, Jentsch TJ, Steinlein OK (1998) A potassium channel mutation in neonatal human epilepsy. Science 279:403-406. CrossRef Medline

Brown BS, Yu SP (2000) Modulation and genetic identification of the M channel. Prog Biophys Mol Biol 73:135-166. CrossRef Medline

Cederquist GY, Azim E, Shnider SJ, Padmanabhan H, Macklis JD (2013) Lmo4 establishes rostral motor cortex projection neuron subtype diversity. J Neurosci 33:6321-6332. CrossRef Medline

Chen HH, Yip JW, Stewart AFR, Frank E (2002) Differential expression of a transcription regulatory factor, the LIM domain only 4 protein Lmo4, in muscle sensory neurons. Development 129:4879-4889. Medline

Duquette PM, Zhou X, Yap NL, MacLaren EJ, Lu JJ, Wallace VA, Chen HH (2010) Loss of LMO4 in the retina leads to reduction of GABAergic amacrine cells and functional deficits. PLoS One 5:e13232. CrossRef Medline

Fox AP, Nowycky MC, Tsien RW (1987) Kinetic and pharmacological properties distinguishing three types of calcium currents in chick sensory neurones. J Physiol 394:149-172. Medline

Ghamari-Langroudi M, Srisai D, Cone RD (2011) Multinodal regulation of the arcuate/paraventricular nucleus circuit by leptin. Proc Natl Acad Sci U S A 108:355-360. CrossRef Medline 
Hahm K, Sum EY, Fujiwara Y, Lindeman GJ, Visvader JE, Orkin SH (2004) Defective neural tube closure and anteroposterior patterning in mice lacking the LIM protein LMO4 or its interacting partner Deaf-1. Mol Cell Biol 24:2074-2082. CrossRef Medline

Holder JL Jr, Butte NF, Zinn AR (2000) Profound obesity associated with a balanced translocation that disrupts the SIM1 gene. Hum Mol Genet 9:101-108. CrossRef Medline

Hrabovszky E, Wittmann G, Turi GF, Liposits Z, Fekete C (2005) Hypophysiotropic thyrotropin-releasing hormone and corticotropin-releasing hormone neurons of the rat contain vesicular glutamate transporter-2. Endocrinology 146:341-347. CrossRef Medline

Hur EE, Zaborszky L (2005) Vglut2 afferents to the medial prefrontal and primary somatosensory cortices: a combined retrograde tracing in situ hybridization study [corrected]. J Comp Neurol 483:351-373. CrossRef Medline

Joshi K, Lee S, Lee B, Lee JW, Lee SK (2009) LMO4 controls the balance between excitatory and inhibitory spinal V2 interneurons. Neuron 61: 839-851. CrossRef Medline

Kashani AH, Qiu Z, Jurata L, Lee SK, Pfaff S, Goebbels S, Nave KA, Ghosh A (2006) Calcium activation of the LMO4 transcription complex and its role in the patterning of thalamocortical connections. J Neurosci 26: 8398-8408. CrossRef Medline

Kublaoui BM, Gemelli T, Tolson KP, Wang Y, Zinn AR (2008) Oxytocin deficiency mediates hyperphagic obesity of $\operatorname{Sim} 1$ haploinsufficient mice. Mol Endocrinol 22:1723-1734. CrossRef Medline

Lantz KA, Hart SG, Planey SL, Roitman MF, Ruiz-White IA, Wolfe HR, McLane MP (2010) Inhibition of PTP1B by trodusquemine (MSI-1436) causes fat-specific weight loss in diet-induced obese mice. Obesity (Silver Spring) 18:1516-1523. CrossRef Medline

Luther JA, Daftary SS, Boudaba C, Gould GC, Halmos KC, Tasker JG (2002) Neurosecretory and non-neurosecretory parvocellular neurones of the hypothalamic paraventricular nucleus express distinct electrophysiological properties. J Neuroendocrinol 14:929-932. CrossRef Medline

Mao X, Fujiwara Y, Chapdelaine A, Yang H, Orkin SH (2001) Activation of EGFP expression by Cre-mediated excision in a new ROSA26 reporter mouse strain. Blood 97:324-326. CrossRef Medline

Pandey NR, Zhou X, Qin Z, Zaman T, Gomez-Smith M, Keyhanian K, Anisman H, Brunel JM, Stewart AF, Chen HH (2013) The LIM domain only 4 protein is a metabolic responsive inhibitor of protein tyrosine phosphatase 1B that controls hypothalamic leptin signaling. J Neurosci 33:1264712655. CrossRef Medline

Perez-Reyes E (2003) Molecular physiology of low-voltage-activated T-type calcium channels. Physiol Rev 83:117-161. CrossRef Medline

Qin Z, Zhou X, Gomez-Smith M, Pandey NR, Lee KF, Lagace DC, Béïque JC, Chen HH (2012) LIM domain only 4 (LMO4) regulates calciuminduced calcium release and synaptic plasticity in the hippocampus. J Neurosci 32:4271-4283. CrossRef Medline

Rosin DL, Weston MC, Sevigny CP, Stornetta RL, Guyenet PG (2003) Hypothalamic orexin (hypocretin) neurons express vesicular glutamate transporters VGLUT1 or VGLUT2. J Comp Neurol 465:593-603. CrossRef Medline

Sakurai T, Nagata R, Yamanaka A, Kawamura H, Tsujino N, Muraki Y, Kageyama H, Kunita S, Takahashi S, Goto K, Koyama Y, Shioda S, Yanagisawa M (2005) Input of orexin/hypocretin neurons revealed by a genetically encoded tracer in mice. Neuron 46:297-308. CrossRef Medline

Schock SC, Xu J, Duquette PM, Qin Z, Lewandowski AJ, Rai PS, Thompson
CS, Seifert EL, Harper ME, Chen HH (2008) Rescue of neurons from ischemic injury by PPAR $\gamma$ requires a novel essential cofactor LMO4. J Neurosci 28:12433-12444. CrossRef Medline

Sternson SM (2013) Hypothalamic survival circuits: blueprints for purposive behaviors. Neuron 77:810-824. CrossRef Medline

Stocker SD, Simmons JR, Stornetta RL, Toney GM, Guyenet PG (2006) Water deprivation activates a glutamatergic projection from the hypothalamic paraventricular nucleus to the rostral ventrolateral medulla. J Comp Neurol 494:673-685. CrossRef Medline

Stotz-Potter EH, Willis LR, DiMicco JA (1996) Muscimol acts in dorsomedial but not paraventricular hypothalamic nucleus to suppress cardiovascular effects of stress. J Neurosci 16:1173-1179. Medline

Sun QQ, Huguenard JR, Prince DA (2001) Neuropeptide Y receptors differentially modulate $\mathrm{G}$-protein-activated inwardly rectifying $\mathrm{K}^{+}$channels and high-voltage-activated $\mathrm{Ca}^{2+}$ channels in rat thalamic neurons. J Physiol 531:67-79. CrossRef Medline

Suzuki S, Rogawski MA (1989) T-type calcium channels mediate the transition between tonic and phasic firing in thalamic neurons. Proc Natl Acad Sci U S A 86:7228-7232. CrossRef Medline

Swaab DF, Purba JS, Hofman MA (1995) Alterations in the hypothalamic paraventricular nucleus and its oxytocin neurons (putative satiety cells) in Prader-Willi syndrome: a study of five cases. J Clin Endocrinol Metab 80:573-579. CrossRef Medline

Tse E, Smith AJ, Hunt S, Lavenir I, Forster A, Warren AJ, Grutz G, Foroni L, Carlton MB, Colledge WH, Boehm T, Rabbitts TH (2004) Null mutation of the Lmo4 gene or a combined null mutation of the Lmo1/Lmo3 genes causes perinatal lethality, and Lmo4 controls neural tube development in mice. Mol Cell Biol 24:2063-2073. CrossRef Medline

Tsien RW (1983) Calcium channels in excitable cell membranes. Annu Rev Physiol 45:341-358. CrossRef Medline

van Loo KM, Schaub C, Pernhorst K, Yaari Y, Beck H, Schoch S, Becker AJ (2012) Transcriptional regulation of T-type calcium channel CaV3.2: bi-directionality by early growth response 1 (Egr1) and repressor element 1 (RE-1) protein-silencing transcription factor (REST). J Biol Chem 287: 15489-15501. CrossRef Medline

Wang HS, Pan Z, Shi W, Brown BS, Wymore RS, Cohen IS, Dixon JE, McKinnon D (1998) KCNQ2 and KCNQ3 potassium channel subunits: molecular correlates of the M-channel. Science 282:1890-1893. CrossRef Medline

Wu Z, Xu Y, Zhu Y, Sutton AK, Zhao R, Lowell BB, Olson DP, Tong Q (2012) An obligate role of oxytocin neurons in diet induced energy expenditure. PLoS One 7:e45167. CrossRef Medline

Xu Y, Tong Q (2011) Expanding neurotransmitters in the hypothalamic neurocircuitry for energy balance regulation. Protein Cell 2:800-813. CrossRef Medline

Zaman T, Lee K, Park C, Paydar A, Choi JH, Cheong E, Lee CJ, Shin HS (2011) Cav2.3 channels are critical for oscillatory burst discharges in the reticular thalamus and absence epilepsy. Neuron 70:95-108. CrossRef Medline

Zhou X, Gomez-Smith M, Qin Z, Duquette PM, Cardenas-Blanco A, Rai PS, Harper ME, Tsai EC, Anisman H, Chen HH (2012) Ablation of LMO4 in glutamatergic neurons impairs leptin control of fat metabolism. Cell Mol Life Sci 69:819-828. CrossRef Medline

Ziegler DR, Cullinan WE, Herman JP (2002) Distribution of vesicular glutamate transporter mRNA in rat hypothalamus. J Comp Neurol 448:217229. CrossRef Medline 